\title{
Hepatitis B virus infection and its associated factors among medical waste collectors at public health facilities in eastern Ethiopia: a facility-based cross- sectional study
}

Degu Abate Mengiste ${ }^{1}$, Abebe Tolera Dirbsa ${ }^{2^{*}}$, Behailu Hawulte Ayele ${ }^{3}$ and Tewodros Tesfa Hailegiyorgis ${ }^{4}$

\begin{abstract}
Background: The risk of hepatitis B virus infection among medical waste handlers who undergo collection, transportation, and disposal of medical wastes in the health institutions is higher due to frequent exposure to contaminated blood and other body fluids. There is limited evidence on the seroprevalence of hepatitis B among medical waste handlers in eastern Ethiopia. The study was aimed at studying the seroprevalence of Hepatitis B Virus and associated risk factors among medical waste collectors at health facilities of eastern Ethiopia.

Methods: A facility-based cross-sectional study was conducted among randomly selected medical waste collectors from public health facilities in eastern Ethiopia from March to June 2018. A pre-tested and well-structured questionnaire was used to collect data on socio-demographic characteristics and hepatitis B infection risk factors. A $2.5 \mathrm{ml}$ venous blood was also collected, centrifuged and the serum was analyzed for hepatitis B surface antigen using the instant hepatitis B surface antigen kit. Descriptive summary measures were done. Chi-square and Fisher exact tests were used to assess the risk of association. Multivariate logistic regression was conducted with $95 \% \mathrm{Cl}$ and all value at $P$-value $<0.05$ was declared statistically significant.
\end{abstract}

Results: From a total of 260 (97.38\%) medical waste collectors participated, HBV was detected in 53 (20.4\%) of the participants $[95 \% \mathrm{Cl} ; 15.8,25.6]$. No significant differences were observed in the detection rates of HBV with respect to socio-demographic characteristics. In both bivariate and multivariable logistic regression analysis, being unvaccinated $(\mathrm{AOR}=6.35 ; 95 \% \mathrm{Cl}=[2.53-15.96], P=0.001)$, history of blood transfusion (receiving) $(\mathrm{AOR} ; 3.54 ; 95 \% \mathrm{Cl}$; $[1.02-12.24], P=0.046)$, history of tattooing ( $A O R=2.86 ; 95 \% \mathrm{Cl}=[1.12-7.27], P=0.03)$, and history of multiple sexual partner $(A O R=10.28 ; 95 \% \mathrm{Cl}=[4.16-25.38], \mathrm{P}=0.001)$ remained statistically significantly associated with $\mathrm{HBsAg}$ positivity.

\footnotetext{
* Correspondence: komiintolera@gmail.com

${ }^{2}$ Epidemiology and Biostatistics Unit, College of Health and Medical Sciences, School of Public Health, Haramaya University, P.O. Box, 235, Harar, Ethiopia

Full list of author information is available at the end of the article
}

(c) The Author(s). 2021 Open Access This article is licensed under a Creative Commons Attribution 4.0 International License, which permits use, sharing, adaptation, distribution and reproduction in any medium or format, as long as you give appropriate credit to the original author(s) and the source, provide a link to the Creative Commons licence, and indicate if changes were made. The images or other third party material in this article are included in the article's Creative Commons. licence, unless indicated otherwise in a credit line to the material. If material is not included in the article's Creative Commons licence and your intended use is not permitted by statutory regulation or exceeds the permitted use, you will need to obtain permission directly from the copyright holder. To view a copy of this licence, visit http://creativecommons.org/licenses/by/4.0/ The Creative Commons Public Domain Dedication waiver (http://creativecommons.org/publicdomain/zero/1.0/) applies to the data made available in this article, unless otherwise stated in a credit line to the data. 
(Continued from previous page)

Conclusion: This cross-sectional study identified that HBV infection is high among medical waste collectors in eastern Ethiopia. Immunization and on job health promotion and disease prevention measures should be considered in order to control the risk of HBV infection among medical waste collectors in eastern Ethiopia.

Keywords: Seroprevalence, Occupational exposure, Medical waste, Sharps injuries, Eastern Ethiopia

\section{Introduction}

Improper management of waste produced in the course of healthcare activity carries a high risk of environmental hazards and public health risks [1-3]. Occupational exposure to percutaneous needle sticks injuries during segregation or recapping, for example, pose a significant risk of occupational transmission of blood borne pathogens such as human immunodeficiency virus (HIV), hepatitis $B$ virus (HBV) and hepatitis $\mathrm{C}$ virus (HCV) particularly among medical waste handlers (MWHs) [4-6]. Hepatitis B virus causes liver inflammation, which may lead to fibrosis, cirrhosis, or liver cancer $[7,8]$ and it is usually transmitted through contact with infected body fluids, such as blood, semen, and percutaneous injuries [9].

Estimates from the World Health Organization (WHO) indicate that in 2015, an estimated 257 million people were living with chronic HBV infection. Chronic HBV epidemics mostly affected the WHO African Region and the Western Pacific Region which account for $68 \%$ of those infected. Furthermore, mortality from viral hepatitis has increased by $22 \%$ since 2000 [10]. Some literature in Ethiopia indicates that HBV infection among medical waste collectors ranges between 6 and $6.3 \%$ [11, 12 ] and an overall pooled prevalence of $8 \% \mathrm{HBV}$ among the community [13]. Hepatitis $B$ vaccine coverage with the initial birth dose vaccination is still low at 39\% and other prevention interventions are insufficiently implemented [10].

Medical waste handlers are highly involved in health care waste management including waste segregation, transportation, storage, treatment, and final disposal of all types of waste generated in the health care facilities that require a high standard of training [14, 15]. High prevalence of HBV infection occurred in public health center cleaners (PHCCs) and exposure increased with the amount of waste generated that increase as the number of patients flow increases [16].

This was reported in some cases mainly due to a high level of non-compliance to standard medical waste management procedures [17] or unavailability of post-exposure prophylaxis [18, 19]. Despite national and international efforts to minimize occupational hazard through raising awareness and seeking solutions to the problems associated with healthcare waste management for many years, health care waste management (HCWM) have failed and health care workers particular medical waste handlers are continuing to be at increased risk of HBV infection [15, 20]. Reports indicate that access to affordable hepatitis testing is limited and only a few people with viral hepatitis have been diagnosed (9\% of HBV infected persons) [10]. Information on the spread of infection resulting from waste handling in eastern Ethiopia is limited. Therefore, this study was conducted to identify the magnitude of $\mathrm{HBV}$ infection among MWHs and its associated factors.

\section{Methods and materials Study design and setting}

A facility-based cross-sectional study was conducted in public health facilities of Harari region, Diredawa administration, and east and west Hararghe zones of Oromia regional state, eastern Ethiopia, from March to June 2018. According to the data obtained from the respective health offices, there were around 211 public health facilities (11 hospitals and 200 health centers) in the study area (115 health centers and 5 hospitals are found in east Hararghe, 65 health centers and 2 hospitals in west Hararghe, 12 health centers and 2 hospitals in Diredawa, and 8 health centers and 2 hospitals in Harar) (Fig. 1).

\section{Participants and sampling procedures}

Multistage sampling technique was used and facilities were then stratified into hospitals and health centers. Eleven Hospitals and 30 health centers were selected from a total of 211 health facilities in eastern Ethiopia by lottery method. Sample size was determined using single population proportion formula for both objectives. Accordingly, sample size was calculated considering a beta of $80 \%$ and an alpha of $0.05 \%$ and design effect of 1.5 . It was estimated 267 samples were needed which was obtained with the second objective (risk factors for HBV infection) from previous study by Anagaw et al. [12]. The Study participants were then proportionally allocated for respective selected health institutions based on the number of study population working at each selected health institution. Registered lists of study participants were used as sampling frame. 


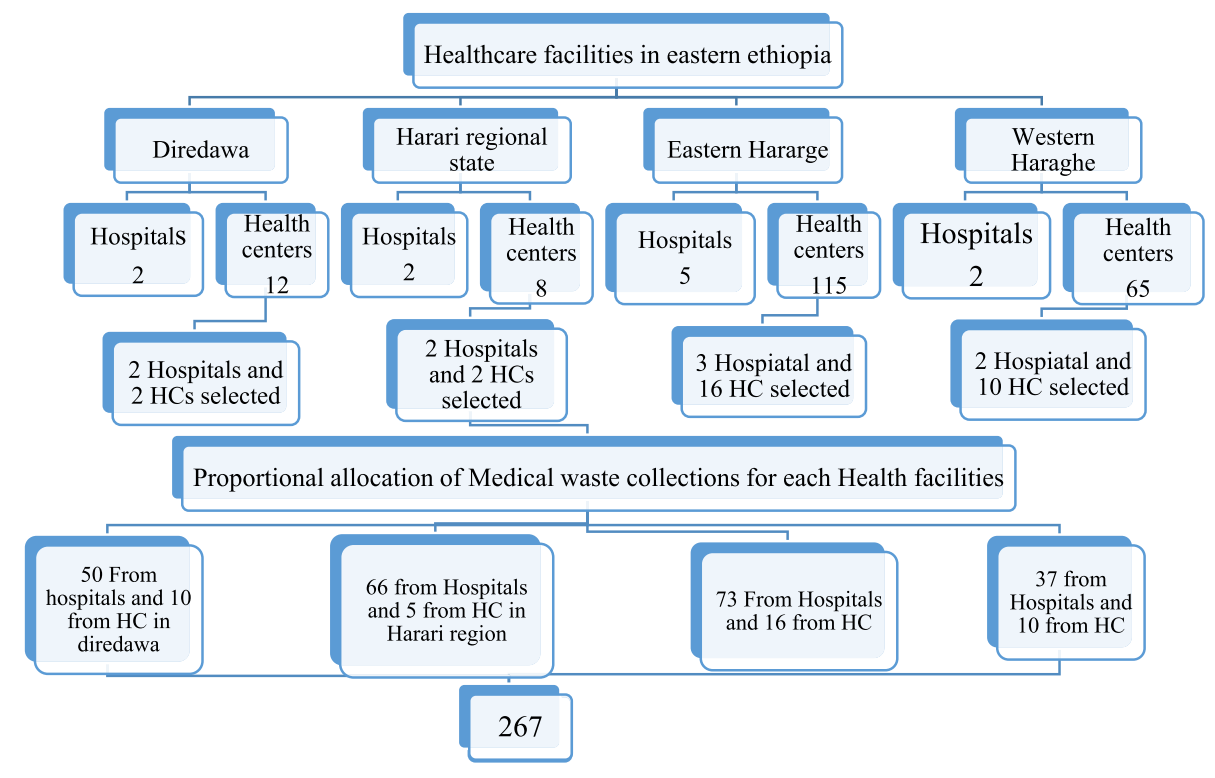

Fig. 1 Flow diagram of Health facility and participant selection for HBV infection study in Eastern Ethiopia, 2018 (NB: HC; Health center)

\section{Inclusion and exclusion criteria}

All medical waste collectors who were working at health facilities and healthy enough to provide information were included. Those medical waste collectors who were critically ill, have mental problem and have not engaged/ exposed to medical waste management were excluded.

The primary outcome of this study was prevalence of HBV infection and our secondary outcome were factors associated with HBV infections such as socio demographic characteristics, occupational exposure to medical waste, immunization with hepatitis B virus vaccines, blood transfusions, multiple sexual partners, and family history of liver disease and others non-occupational risk factors.

\section{Data collection and data quality control}

A pretested structured questionnaire was used for data collection from medical waste collectors. Five Nurses and five Public health professionals were recruited to facilitate data collection. The questionnaire was developed after reviewing different literature and pretested on $5 \%$ of sample size working at hospital which were not included in the study [11, 12, 21, 22]. The questionnaire was translated to local language (Afan Oromo and Amharic). During data collection, the data was checked for its completeness each day by supervisors and investigators after it was collected. For blood sample collection, all material we used were tested before purchase. Blood sample was collected with standard precaution and centrifuged to separate serum from whole blood immediately after collection of blood.

\section{Blood sample}

Five laboratory professionals were recruited to collect blood sample. $2.5 \mathrm{ml}$ of venous blood samples was collected in tubes aseptically after written consents was obtained from study subjects. Serum was separated by centrifugation at $3000 \mathrm{r} / \mathrm{min}$ for $5 \mathrm{~min}$ after the blood was clotted. The blood samples were labeled with unique identification numbers. The serum was separated by centrifugation and was placed into Eppendorf tubes. The serological tests were performed using hepatitis B surface antigen rapid test kits by Wondfo one step HBsAg test strip according to the manufacturer's manual (Guangzhou Wondfo Biotech Co., Ltd. (Wondfo)). This test strip has sensitivity and specificity of 96.2 and $99.3 \%$ respectively [23].

\section{Data processing and analysis}

Collected data was entered into Epi-data Version 3.1 and exported to SPSS version 22 statistical packages for analysis. Descriptive summary measures were made using frequency table, percentage and mean and standard deviation. Chi-square and Fisher exact tests were used to assess risk of association.

The variables with a $p$-value of less than 0.2 in the bivariate analysis were included in the multivariable analysis. Multivariable logistic regression (adjusted odds ratio with $95 \%$ confidence interval) analysis was employed to identify independent variables associated with HBV infections adjusting for other variables. Model fitness was checked using Hosmer Lemeshow goodness of fit and variables with $P$-value $<0.05$ at $95 \%$ CI was declared statistical significance. 


\section{Ethical considerations}

The study protocol was approved by Institutional Health Research Ethics Review Committee (IHRERC) of Haramaya University, College of Health and Medical Sciences (CHMS) and permission for study proceeding was accepted by respective health institutions. Then, written and signed informed consent was obtained from each participant. In order to protect the confidentiality of the information, names and identity number of participants were not included in the questionnaires. Results were communicated to study subjects and subjects with positive test were refereed for further investigations and follow-ups.

\section{Result}

\section{Socio-demographic characteristics of the study} participants

A total of 260 (97.38\%) medical waste collectors have participated in this study. Seven participants refused to participate in this study. Two hundred thirty-seven (91.2\%) participants were females (Table 1). The median age of the study participant was 29 years $(\mathrm{IQR}=8)$. The majority $(58.1 \%)$ of the study participants were married whereas the median years of service was 4 years $(\mathrm{IQR}=$ 4) (Table 1).
Prevalence of hepatitis B infection among study subjects According to this study, 20.4\% [95\% CI; 15.8, 25.6] of the respondents are found positive for HBsAg test. There was no statistically significant difference in the rate of HBV infection between socio-demographic characteristics of the study participants $(P>0.05)$. Of note, statistically significant difference was noted in exposure to blood ungloved $(P=0.002)$, history of multiple sexual partner $(P=0.001)$, and being unvaccinated for HBV $(P=0.001)$.

\section{Knowledge, training and waste handling practices}

According to this study, 51.9\% (135) of the study participants have poor knowledge on universal precaution guideline and only $39.6 \%$ (103) have participated in training program about infection prevention or universal precaution. More than two third (76.9\%) said they cleaned their hand after touching or collection of blood or other body fluids. Two hundred two (85.4\%) study subjects said they wear glove consistently for personal protective purpose. On the other hand, about one half, $43.1 \%$ of the study participants have history of exposure to any types of body fluids like waste contaminated by body fluids (blood, peritoneal, pericardial, pleural, synovial, CSF amniotic fluids and others). Out of these

Table 1 Sociodemographic characteristics the study participants in public health facilities in eastern Ethiopia, 2018

\begin{tabular}{|c|c|c|c|}
\hline Variables & Category & Frequency & Percent (\%) \\
\hline \multirow[t]{2}{*}{ Sex } & Male & 23 & 8.8 \\
\hline & Female & 237 & 91.2 \\
\hline \multirow[t]{6}{*}{ Educational status } & Unable to read and write & 21 & 8.1 \\
\hline & Can read and write & 30 & 11.5 \\
\hline & Grade 1-8 & 72 & 27.7 \\
\hline & Grade 9-10 & 79 & 30.4 \\
\hline & Grade 12 & 26 & 10 \\
\hline & Diploma and above & 32 & 12.3 \\
\hline \multirow[t]{4}{*}{ Marital status } & Single/unmarried & 79 & 30.4 \\
\hline & Married & 151 & 58.1 \\
\hline & Divorced & 25 & 8.7 \\
\hline & Widowed & 5 & 1.9 \\
\hline \multirow[t]{3}{*}{ Religion } & Orthodox & 141 & 54.2 \\
\hline & Muslim & 101 & 38.8 \\
\hline & Protestant & 18 & 6.9 \\
\hline \multirow[t]{3}{*}{ Ethnicity } & Amhara & 129 & 46.6 \\
\hline & Oromo & 114 & 43.8 \\
\hline & Others $^{*}$ & 17 & 6.6 \\
\hline \multirow[t]{2}{*}{ Average monthly income } & Earns between 20 and 55 US\$ & 244 & 93.8 \\
\hline & Earns between 56 and 107 US\$ & 16 & 6.2 \\
\hline
\end{tabular}

NB: Average monthly income was calculated based on Ethiopian government employee monthly salary in Ethiopian birr and converted to United states dollar Others ${ }^{*}=$ Harari, Tigray, Gurage

US\$: United states dollar 
study participants, $61.61 \%$ have history of exposure to blood ungloved. The majority $52.69 \%$ (137) of the study participants said they have recapped needle that were in appropriately recapped. About $41.2 \%$ (107) of study participants said they had history of sharp material injury, and 38.5\% (100) had history of needle stick injury. Fourth eight $(44.86 \%)$ of the study participants had had sharp injury twice (Table 2). There was no significant difference in HBsAg positivity with respect to frequency of sharp injury ( $p$ value $>0.05)$.

Thirty-five (13.5\%) study subjects said they had history of surgical operation. Approximately 9\% (23) of the study participants had participated in blood transfusion. Furthermore, $11.5 \%$ (30) of the study participants said they have been diagnosed with jaundice and/or liver diseases, and $12.3 \%$ (32), and $22.7 \%$ (59), had history of tattooing and tooth extraction respectively. From the total study subjects, $8.1 \%$ (21) said that they had history of multiple sexual partners in the last 1 year out of which $3.8 \%$ (10) had sex with commercial sex workers. Eleven study subjects $(4.1 \%)$ said that they had family history of chronic liver disease. Among the total study subjects, $51.2 \%$ (133) said that they have been vaccinated for HBV.

\section{Factors associated with HBV infection among the study population}

Sex, wearing personal protective equipment (PPE), exposure to blood ungloved, history of sharp injury, history of operation/surgery, history of blood transfusion, history of tattooing, history of multiple sexual partners, and vaccination status for HBV were entered into the model as these variables had $p$-value less than 0.2 in bivariate analysis.

Study subjects who have never been vaccinated for HBV were 6.35 (AOR $=6.35$; 95\% CI: $[2.53-15.96])$ times more likely to be positive for HBsAg compared to those who have been vaccinated for HBV (Table 3). Medical waste collectors who had history of blood transfusion (received) and tattooing were 3.54 and 2.86 times (AOR; 3.54; 95\%CI, [1.02-12.24]; AOR $=2.86$; 95\% CI: $[1.12-$ 7.27]) more likely to be positive for HBsAg than their counterparts respectively (Table 3 ). Furthermore, the

Table 2 Frequency of sharp injury among medical waste handlers/collectors in public health facilities in eastern Ethiopia, 2018

\begin{tabular}{llll}
\hline Frequency of sharp injury & Frequency & Percent (\%) \\
\hline Valid & Once & 41 & 38.31 \\
& Twice & 48 & 44.86 \\
& Three times & 7 & 6.54 \\
Several times & 11 & 10.28 \\
& Total & 107 & 100 \\
\hline
\end{tabular}

odds of being positive for HBV infection is 10.28 (AOR = 10.28; 95\%CI: [4.16-25.38]) times higher among medical waste collectors who had multiple sexual partners in the last 1 years than those who had no history of multiple sexual partners.

\section{Discussion}

This study demonstrated that the seroprevalence of hepatitis B virus infection was high (20.4\%). This finding is much higher than a study from Tripoli Libya [21], northern Ethiopia [12], southern Ethiopia [1], Northwest Ethiopia [24] and Addis Ababa [11]. Low training coverage, being unvaccinated, history of multiple sexual partner and poor knowledge on universal precaution guideline among our study groups may explain this high infection rate.

This study revealed that the odds of being positive for HBsAg was higher among medical waste collectors who have never been vaccinated compared to those who have been vaccinated for HBV. This finding is similar with study conducted in Thailand [25], Libya [21] and northern Tanzania [26]. HBV vaccines was found to be protective against HBV infection [26] which constituted a land mark of great importance for workers in health care facilities including medical waste collectors. However, lack of universal availability of the vaccine for adult population in Ethiopia [12, 27] may explain this finding. In addition, this study finding indicates the health facilities in this study do not take appropriate steps to ensure workers safety necessary to avoid occupational hazards. This indicates the need for training on universal precaution guideline, health promotion and scale up of HBV vaccination.

Blood transfusion (receiving) has been found to be a risk factor for HBV infection among our study group. Those who received blood donation were 3.5 more likely to be positive for HBV than their counterpart. This finding is similar with study in Spain [28], Japan [29], Nigeria [30, 31], Conakry Guinea [32]. Despite increasing screening of blood for HBV before giving to patients, the remaining residual risk of transfusion transmission of HBV infection remain high due to suboptimal screening practice $[31,33]$. This finding is in contrast to the current practice by most of the local blood bank centers in Ethiopia which screen blood for safe blood transfusion to prevent transfusion-transmitted infections [34]. The national policy of Ethiopia on communicable disease prevention and control also give special emphasis for screening of donors' blood prior to blood transfusion $[35,36]$. In addition, this finding is in contrast to study by Alter where transmission of HBV via transfusion or transplant has been virtually eliminated in countries that test donors for $\mathrm{HBsAg}$ and virally inactivate plasmaderived products [6]. 
Table 3 Factors associated with HBsAg positive status among medical waste handlers/collectors in Public health facilities in eastern Ethiopia, $2019(n=260)$

\begin{tabular}{|c|c|c|c|c|c|c|}
\hline \multirow[t]{2}{*}{ Variables } & \multirow[t]{2}{*}{ Response } & \multicolumn{2}{|c|}{ HBsAg status } & \multirow[t]{2}{*}{ COR $[95 \% \mathrm{Cl}]$} & \multirow[t]{2}{*}{ AOR $[95 \% \mathrm{Cl}]$} & \multirow{2}{*}{$\begin{array}{l}\mathrm{P} \text { - } \\
\text { value }\end{array}$} \\
\hline & & Positive & Negative & & & \\
\hline \multirow[t]{2}{*}{ Sex } & Male & 8 & 15 & 1 & 1 & \\
\hline & Female & 45 & 192 & $2.28(0.91-5.70)$ & $0.53[0.16-1.69]$ & 0.28 \\
\hline \multirow[t]{2}{*}{ Wear PPE } & Yes & 45 & 190 & 1 & 1 & \\
\hline & No & 8 & 17 & $1.99(0.81-4.89)$ & $1.34[0.46-3.91]$ & 0.59 \\
\hline \multirow[t]{2}{*}{ Ever vaccinated for HBV } & Yes & 13 & 120 & 1 & 1 & \\
\hline & No & 40 & 87 & $4.24(2.14-8.41)$ & $6.35[2.53-15.96]$ & 0.001 \\
\hline \multirow[t]{2}{*}{ History of sharp injury } & No & 26 & 127 & 1 & 1 & \\
\hline & yes & 27 & 80 & $1.65(0.90-3.02)$ & $1.54[0.73-3.27]$ & 0.25 \\
\hline \multirow[t]{2}{*}{ History of operation/surgery } & No & 49 & 176 & 1 & 1 & \\
\hline & Yes & 4 & 31 & $0.46(0.16-1.38)$ & $0.89[0.24-3.26]$ & 0.86 \\
\hline \multirow[t]{2}{*}{ History of blood transfusion } & No & 45 & 192 & 1 & 1 & \\
\hline & Yes & 8 & 15 & $2.28(0.91-5.70)$ & $3.54[1.02-12.24]$ & 0.046 \\
\hline \multirow[t]{2}{*}{ History of tattooing } & No & 41 & 187 & 1 & 1 & \\
\hline & Yes & 12 & 20 & $2.74(1.24-6.04)$ & $2.86[1.12-7.27]$ & 0.03 \\
\hline \multirow[t]{2}{*}{ History of multiple sexual partner } & No & 32 & 191 & 1 & 1 & \\
\hline & Yes & 21 & 16 & $7.83(3.70-16.60)$ & $10.28[4.16-25.38]$ & 0.001 \\
\hline \multirow[t]{2}{*}{ Exposure to blood ungloved } & No & 30 & 161 & 1 & 1 & \\
\hline & Yes & 23 & 46 & $2.68(1.42-5.06)$ & $1.69[0.77-3.71]$ & 0.92 \\
\hline
\end{tabular}

Literature indicated that HBV transmissions can result from non-compliance with aseptic techniques during procedures such as surgery or tattooing that resulted in cross-contamination of medical equipment and devices $[37,38]$. Previous history of tattooing significantly increased the odds of HBV infection by 3 times than those with no history of tattooing. Previous studies have also identified that the rate of lifetime exposure to HBV infection was significantly higher among medical waste handlers who had received a tattoo [1].

Perinatal and sexual exposures to HBV are also highly efficient modes of transmission [6, 39-41]. In this study, those who had multiple sexual partners in the last 1 year were almost 10 times more like to be infected by HBV than their counterparts. This finding is similar to studies conducted in Tigray Ethiopia [28], North-west Ethiopia $[24,42]$ Slovakia [43] and in Iran [44]. This is a scientifically well-established fact where parental and sexual route play an important role in the transmission of HBV.

Though not significant, training provided by health facilities in this study area to medical waste collectors were inadequate and lack regularity. This is similar with other study finding in Ethiopia [12]. Sufficient training should be given for medical waste collectors on waste handling, internal transport, spill management and storage requirements for the different types of wastes arising at the facility to minimize the risk of injury associated with waste handling.

None of socio-demographic characteristics and occupational exposures such as not wearing personal protective equipment, exposure to blood ungloved, history of sharp injury, surgical operations, liver disease, tooth extraction, blood transfusion, and family history of liver disease were shown statistically significant association with HBV infection in this study. However; the rate of occurrence of body fluid exposure to mucous membranes and blunt-penetrating injuries in work sites were higher. Furthermore, training on universal precaution guideline was low where on $39.6 \%$ were trained for short duration.

\section{Strength and limitation of the study}

This study is a large-scale study including many health facilities and geographic areas which may increase its representativeness of the finding. However, we recognized certain limitations including insufficient immunoassay logistics supply which restricted this study to provide data on other $\mathrm{HBV}$ serological markers as HBeAg, IgM and IgG anti-HBc". In addition, the use of rapid tests in the absence of confirmatory conventional immunoassays may be also a limitation. This limited the study classifying whether infections are acute or chronic 
and whether the degree of infectivity correlates with a high level of HBV replication or not.

\section{Conclusions}

The prevalence of hepatitis B virus infection among medical waste collectors was higher in public health facilities in eastern Ethiopia compared to other findings. Occupational exposure due to being unvaccinated, infection due to tattooing, blood transfusion and history of multiple sexual partners were significant factors associated with high HBV infection. Medical waste collectors also had poor awareness of viral hepatitis B infection prevention and had low training on universal precaution guidelines. These findings highlight the need for continues improvement of working environment of medical waste collectors on provision of occupation precautions and health promotion. These health institutions should promptly adopt procedures and policies for occupation protection of their workers through continuous training and health promotion to improve their health knowledge. Effective scale up of free hepatitis B vaccine and adoption of more safe ways for waste collection could be considered in order to control the risk of HBV infection.

\section{Supplementary Information}

The online version contains supplementary material available at https://doi. org/10.1186/s12879-021-05918-x

\section{Additional file 1.}

\section{Acknowledgments}

We thank all of the staff at Harari region, Dire Dawa city Administration, west Hararghe and east Hararghe zone administrations and health facilities for providing organizational support. We would like to extent our appreciation for all of our data collectors and supervisors. Lastly we would like to acknowledge Haramaya University for funding this study.

\section{Authors' contributions}

$\mathrm{DA}$ and $\Pi \mathrm{T}$ conceived the study and drafted the proposal. DA, $\Pi$ and $\mathrm{BH}$ had substantial contributions to the study design and development of the data collection checklist. AT drafted the manuscript. DA, BH, AT and TT wrote and corrected the manuscript. All authors read the manuscript and approved it.

\section{Funding}

This work was funded by Research Affairs Office of Haramaya University.

\section{Availability of data and materials}

Most of the data generated or analyzed during this study are included in this published article. The full datasets used and/or analyzed during the current study is available from the corresponding author on reasonable request.

\section{Ethics approval and consent to participate}

The study protocol was approved by Institutional Health Research Ethics Review Committee (IHRERC) of Haramaya University, College of Health and Medical Sciences (CHMS) (Reference number: IHRERC/093/2017) and permission for study proceeding was accepted by respective health institutions. All methods were carried out in accordance with relevant guidelines and regulations of Haramaya University. Thus, informed, written and signed consent was obtained from each participant. In order to protect the confidentiality of the information, names and identity number of participants were not included in the questionnaires. The approved letter from IHRERC of Haramaya University, College of Health and Medical Sciences (CHMS) is attached in Supplementary files.

Consent to participate from study subjects were written and signed individually on hard copy. Thus, it is not possible to submit all consents form.

\section{Consent for publication}

(Not applicable)

\section{Competing interests}

The authors declare that they have no competing interests.

\section{Author details}

${ }^{1}$ Department of Medical Laboratory Sciences, College of Health and Medical Sciences, Haramaya University, P.O. Box, 235, Harar, Ethiopia. ${ }^{2}$ Epidemiology and Biostatistics Unit, College of Health and Medical Sciences, School of Public Health, Haramaya University, P.O. Box, 235, Harar, Ethiopia. ${ }^{3}$ Public Health and Policy Unit, College of Health and Medical Sciences, School of Public Health, Haramaya University, P.O. Box, 235, Harar, Ethiopia.

${ }^{4}$ Department of Medical Laboratory Sciences, College of Health and Medical Sciences, Haramaya University, P.O. Box, 235, Harar, Ethiopia.

Received: 18 November 2020 Accepted: 17 February 2021

Published online: 27 February 2021

\section{References}

1. Amsalu A, Worku M, Tadesse E, Shimelis T. The exposure rate to hepatitis B and $C$ viruses among medical waste handlers in three government hospitals, southern Ethiopia. Epidemiol Health. 2016:38:e2016001-e.

2. Shiferaw $Y$, Abebe T, Mihret A. Sharps injuries and exposure to blood and bloodstained body fluids involving medical waste handlers. Waste Manag Res. 2012;30(12):1299-305.

3. Jang YC, Lee $\mathrm{C}$, Yoon OS, Kim H. Medical waste management in Korea. J Environ Manag. 2006;80(2):107-15.

4. Rachiotis G, Papagiannis D, Markas D, Thanasias E, Dounias G, Hadjichristodoulou C. Hepatitis B virus infection and waste collection: Prevalence, risk factors, and infection pathway. Am J Ind Med. 2012;55(7): 650-5. https://doi.org/10.1002/ajim.22057.

5. Duffell EF, van de Laar MJW, Amato-Gauci AJ. Enhanced surveillance of hepatitis B in the EU, 2006-2012. J Viral Hepat. 2015;22(7):581-9.

6. Alter MJ. Epidemiology of viral hepatitis and HIV co-infection. J Hepatol. 2006:44:56-9.

7. Zampino R, Boemio A, Sagnelli C, Alessio L, Adinolfi LE, Sagnelli E, et al. Hepatitis B virus burden in developing countries. World J Gastroenterol. 2015;21(42):11941-53.

8. Lok ASF, McMahon BJ. Chronic hepatitis B. Hepatology. 2007:45(2):507-39.

9. WHO. World Health Organization; Hepatitis B; Accessed on 18 July 2018: https://www.who.int/news-room/fact-sheets/detail/hepatitis-b. 2018.

10. WHO. Global hepatitis report, 2017, World Health Organization, ISBN: 978 92-4-156545-5. 83p. https://www.who.int/hepatitis/publications/global-hepa titis-report2017/en/. 2017.

11. Shiferaw $Y$, Abebe $T$, Mihret A. Hepatitis B virus infection among medical waste handlers in Addis Ababa, Ethiopia. BMC Research Notes. 2011:4(1):479.

12. Anagaw B, Shiferaw $Y$, Anagaw B, Belyhun $Y$, Erku W, Biadgelegn $F$, et al. Seroprevalence of hepatitis $B$ and $C$ viruses among medical waste handlers at Gondar town health institutions, Northwest Ethiopia. BMC Research Notes. 2012:5(1):55.

13. Belyhun Y, Maier M, Mulu A, Diro E, Liebert UG. Hepatitis viruses in Ethiopia: a systematic review and meta-analysis. BMC Infect Dis. 2016;16(1):761.

14. Farzadkia M, Moradi A, Mohammadi MS, Jorfi SJWM, Research. Hospital waste management status in Iran: a case study in the teaching hospitals of Iran University of Medical Sciences. Waste Manag Res. 2009;27(4):384-9. https://doi.org/10.1177/0734242X09335703.

15. Harhay MO, Halpern SD, Harhay JS, Olliaro PL. Health care waste management: a neglected and growing public health problem worldwide Tropical Med Int Health. 2009;14(11):1414-7.

16. Debere MK, Gelaye KA, Alamdo AG, Trifa ZM. Assessment of the health care waste generation rates and its management system in hospitals of Addis Ababa, Ethiopia, 2011. BMC Public Health. 2013;13(1):28. 
17. Anozie OB, Lawani LO, Eze JN, Mamah EJ, Onoh RC, Ogah EO, et al. Knowledge, attitude and practice of healthcare managers to medical waste management and occupational safety practices: findings from Southeast Nigeria. J Clin Diagn Res. 2017:11(3):IC01-IC4.

18. Al-Marrani WHM, Al-Shamahy HAJUJPR. Prevalence of HBV and HCV; and their associated risk factors among public health center cleaners at selected Public Health Centers in Sana'a city-Yemen. Journal of Pharmaceutical Research. 2018;3(5):63-67.

19. Otovwe A, Adidatimi PO. Knowledge, Attitude and Practice of standard precaution among Health Care Workers in Federal Medical Centre Yenagoa, Nigeria, IOSR Journal of Pharmacy and Biological Sciences (IOSR-JPBS)e-ISSN: 2278-3008, p-ISSN:2319-7676. Volume 12, Issue 4 Ver. III, PP 79-86, www. iosrjournals.org 2017.

20. de Titto E, Savino AA, Townend WK. Healthcare waste management: the current issues in developing countries. London: SAGE Publications Sage UK; 2012.

21. Franka E, El-Zoka AH, Hussein AH, Elbakosh MM, Arafa AK, Ghenghesh KS. Hepatitis B virus and hepatitis C virus in medical waste handlers in Tripoli, Libya. J Hospital Infection. 2009;72(3):258-61.

22. Mol MPG, Gonçalves JP, Silva EA, Scarponi CF, Greco DB, Cairncross S, et al. Seroprevalence of hepatitis $B$ and $C$ among domestic and healthcare waste handlers in Belo Horizonte, Brazil. Waste Manag Res. 2016;34(9):875-83.

23. Okpokam DC, Kooffreh-Ada M, Okhormhe ZA, Ernest NA, Nna VU. Sensitivity comparison between rapid one-step test strip and ELISA methods in detection of HBsAg among selected chronic liver disease patients in University of Calabar Teaching hospital, Calabar, Nigeria. Asian J Med Sci. 2015;6(5):56-60.

24. Yizengaw E, Getahun T, Geta M, Mulu W, Ashagrie M, Hailu D, et al. Seroprevalence of hepatitis $B$ virus infection and associated factors among health care workers and medical waste handlers in primary hospitals of north-West Ethiopia. Bmc Research Notes. 2018;11(1):437. https://doi.org/1 0.1186/s13104-018-3538-8.

25. Chiarakul S, Eunumjitkul K, Vuttiopas S, Vorapimol A, Kaewkungwal J, Poovorawan YJJ-MAOT. Seroprevalence and risk factors of hepatitis B virus infection among health care workers at the Institute of Neurology 2007; 90(8):1536.

26. Shao ER, Mboya IB, Gunda DW, Ruhangisa FG, Temu EM, Nkwama ML, et al. Seroprevalence of hepatitis B virus infection and associated factors among healthcare workers in northern Tanzania. BMC Infect Dis. 2018;18(1):474.

27. Akibu M, Nurgi S, Tadese M, Tsega WD. Attitude and vaccination status of healthcare workers against hepatitis B infection in a teaching hospital, Ethiopia. Scientifica. 2018;2018.

28. López-Menchero C, Alvarez M, Fernández P, Guzmán M, Ortiz-de-Salazar MI, Arbona C. Evolution of the residual risk of HBV, HCV and HIV transmission through blood transfusion in the region of Valencia, Spain, during a 15-year period (2003-2017). Blood Transfus. 2019;17(6):418-27.

29. Matsumoto C, Tadokoro K, Fujimura K, Hirakawa S, Mitsunaga S, Juji T. Analysis of HBV infection after blood transfusion in Japan through investigation of a comprehensive donor specimen repository. Transfusion. 2001;41(7):878-84.

30. Muktar HM, Suleiman AM, Jones M. Safety of blood transfusion: prevalence of hepatitis B surface antigen in blood donors in Zaria, northern Nigeria. Niger J Surg Res. 2005;7(3):290-2.

31. Olotu AA, Oyelese AO, Salawu L, Audu RA, Okwuraiwe AP, Aboderin AO Occult hepatitis $B$ virus infection in previously screened, blood donors in lleIfe, Nigeria: implications for blood transfusion and stem cell transplantation. Virol J. 2016:13(1):76

32. Loua A, Sow EM, Magassouba FB, Camara M, Baldé MA. Evaluation of residual infectious risk among blood donors in National Center of blood transfusion in Conakry. Transfusion Clinique et Biologique. 2004;11(2):98100.

33. Biadgo B, Shiferaw E, Woldu B, Alene KA, Melku M. Transfusion-transmissible viral infections among blood donors at the North Gondar district blood bank, Northwest Ethiopia: a three year retrospective study. PLoS One. 2017; 12(7):e0180416.

34. Shiferaw F, Letebo M, Bane A. Chronic viral hepatitis: policy, regulation, and strategies for its control and elimination in Ethiopia. BMC Public Health. 2016;16(1):769.

35. Nugent R, Bertram MY, Jan S, Niessen LW, Sassi F, Jamison DT, et al. Investing in non-communicable disease prevention and management to advance the sustainable development goals. Lancet. 2018;391(10134):2029-35.
36. Shiferaw F, Letebo M, Misganaw A, Feleke Y, Gelibo T, Getachew T, et al. Non-communicable Diseases in Ethiopia: Disease burden, gaps in health care delivery and strategic directions. Ethiopian J Health Development. 2018;32(3).

37. Hauri AM, Armstrong GL, Hutin YJJljoS, AIDS. The global burden of disease attributable to contaminated injections given in health care settings 2004: 15(1):7-16.

38. Makuza JD, Rwema JOT, Ntihabose CK, Dushimiyimana D, Umutesi J, Nisingizwe MP, et al. Prevalence of hepatitis B surface antigen ( $\mathrm{HBsAg})$ positivity and its associated factors in Rwanda. BMC Infect Dis. 2019;19(1): 381.

39. MacLachlan JH, Cowie BC. Hepatitis B virus epidemiology. Cold Spring Harb Perspect Med. 2015;5(5):a021410-a.

40. Hwang EW, Cheung R. Global epidemiology of hepatitis B virus (HBV) infection. North Am J Med Sci. 2011;4(1).

41. Alter MJ, Margolis HS. The emergence of hepatitis B as a sexually transmitted disease. Med Clin N Am. 1990;74(6):1529-41.

42. Hundie GB, Raj VS, GebreMichael D, Haagmans BL. Seroepidemiology of hepatitis $B$ and $C$ virus infections among blood donors in Ethiopia. J Med Virol. 2017:89(7):1300-3.

43. Drazilova S, Janicko M, Kristian P, Schreter I, Halanova M, Urbancikova I, et al Prevalence and risk factors for hepatitis B virus infection in Roma and nonRoma people in Slovakia. Int J Environ Res Public Health. 2018;15(5):1047.

44. Taleban R, Moafi M, Ataei B, Yaran M, Nokhodian Z, Kassaian N, et al. Seroprevalence of Hepatitis B Infection and Associated Risk Factors among Drug Users in Drop-in Centers of Isfahan, Iran. Int J Prev Med. 2018;9:46.

\section{Publisher's Note}

Springer Nature remains neutral with regard to jurisdictional claims in published maps and institutional affiliations.

Ready to submit your research? Choose BMC and benefit from:

- fast, convenient online submission

- thorough peer review by experienced researchers in your field

- rapid publication on acceptance

- support for research data, including large and complex data types

- gold Open Access which fosters wider collaboration and increased citations

- maximum visibility for your research: over $100 \mathrm{M}$ website views per year

At $\mathrm{BMC}$, research is always in progress.

Learn more biomedcentral.com/submissions 